\title{
EJEMPLOS DEL GRIEGO RABINICO A LA LUZ DEL TESORO LEXICOGRÁFICO DEL DGE *
}

Rabbinical Greek is defined as the Greek vocabulary which emerged in Aramaic and Hebrew sources from the first century B.C. until the end of the Byzantine period. The study of this vocabulary enlarges our understanding of the lexicon of religious life and political administration in the Roman East, as well as increasing our recognition of phonetical phenomena in the transition from koเvi to Byzantine and Modern Greek. The present work is devoted to the study of the Greek words in Genesis Rabba, a traditional Jewish commentary written in Palestine during the Byzantine period.

The proper use of the $D G E$ and its catalogue was helpful for a better understanding and interpretation of these rabbinical sources and their hellenistic heritage.

\section{INTRODUCCIÓN}

Por "griego rabínico» definimos en el presente estudio el riquísimo vocabulario en este idioma que surge de las fuentes literarias en hebreo y arameo (traducciones del Antiguo Testamento y comentarios, liturgia, textos codificadores de leyes, poesia, mística, etc.) redactadas a partir de

- El presente estudio fue preparado durante mi estadía en el Instituto de Filología del CSIC de Madrid (1987).

Agradezco el permiso de utilizar el fichero del $D G E$ que su redacción puso a mi disposición, y asimismo la asistencia científica de Elvira Gangutia y Pedro Bádenas. Este trabajo se completó en Jerusalén bajo la dirección y constante aliento del Profesor H. B. Rosén. Por último, agradezco el asesoramiento del P. Juan Esquivias, del Instituto Bíblico Pontificio, en la redacción final, y la colaboración de Luis Alberto de Cuenca en la preparación de este artículo para EMERITA.

Cito por el Midrash Génesis Rabba, ed. por J. Theodor y Ch. Albeck, Jerusalén 1965. Asimismo he podido contar con la lectura de mss. llevada a cabo por el equipo del Historical Dictionary of the Hebrew Language (en preparación), Jerusalén, Academy of the Hebrew Language, 1985.

Para la transliteración del hebreo y del arameo sigo las normas de la revista $\mathrm{Se}$ farad del CSIC. 
la destrucción del Segundo Templo hasta fines del período bizantino (siglos I-VII d.C.). El valor de este vocabulario consiste en el testimonio de la lengua en transición de la kotví al bizantino y en la documentación de los términos utilizados en la vida diaria, en el comercio, en el ejército y en la administración pública, y refleja también las corrientes religiosas y filosóficas que florecieron en el Imperio Oriental durante los primeros siglos.

Esta documentación griega fue escrita en caracteres hebraicos «aljamiados», y pese a las dificultades que origina esta transcripción y su interpretación, en ella radica también su importancia, pues permite atestiguar fielmente fenómenos fonéticos que anuncian el paso de la koเví a nuevas formaciones lingüísticas de la lengua bizantina y moderna.

Este vocabulario también incluye palabras de origen latino que fueron asimiladas en el «lenguaje franco» del oriente griego, pasando a ser parte integrante del mismo, pero que ya van señalando las primeras características del latín vulgar.

Los lexicógrafos de la literatura rabínica fueron los primeros en detectar este vocabulario en griego y latín, y seleccionarlo de los textos hebreos y arameos. Ya en plena Edad Media y en Italia, Natan ben Yehiel (1035-1100), escribió el primer diccionario etimólogico, el $\mathrm{He}$ 'Aruk', que incluye la primera clasificación de palabras en lenguas clásicas. Posteriormente apareció el valioso trabajo de Buxtorf (1564-1629) Lexicon talmudicum et rabbinicum ${ }^{2}$, donde su autor da las adecuadas transcripciones del arameo al latín y al griego.

Durante el siglo pasado y a comienzo del presente fueron realizados en el área de la lexicografia talmúdica los importantes trabajos de Levy $^{3}$, Jastrow ${ }^{4}$, Kohut ${ }^{5}$ y Dalman ${ }^{6}$. El primer trabajo dedicado exclusivamente a esta disciplina fue el de S. Krauss, Griechische und lateini1893.

${ }_{1}^{1}$ Natan ben Yeḥiel, $\mathrm{He}$ Aruk, Roma 1475. La edición en uso es la de Lublin

2 J. Buxtorf, Lexicon talmudicum et rabbinicum, Basilea 1639.

3 J. Levy, Chaldäisches Wörterbuch über die Targumim und einen grossen Theil des rabbinischen Schrift thums, Leipzig 1867-68. Se usa más la ed. del mismo diccionario por L. Goldschmidt, Berlin 1924.

4 . Jastrow, Dictionary of the Targumim, the Talmud Babli and Yerushalmi, and the Midrashic literature, Londres-Nueva York, 1886-1903.

5 La meta de A. Kohut fue dar una nueva edición más amplia y corregida con nuevas etimologías y nuevas fuentes del diccionario de Natan ben Yehiel: Aruch Completum, 8 vols., Viena 1872-92. Esta publicación fue corregida y completada por S. Krauss, B. Geiger, I. Loew y B. Murmelstein, Additamenta ad librum "Aruch Completum», Viena 1937.

6 G. Dalman, Aramäisch-neuhebräisches Handwörterbuch zu Targum, Talmud und Midrasch, Gotinga 1938. 
sche Lehnwörter im Talmud und Midrasch 7 , Viena 1898. En el primer tomo incluye una importante introducción gramatical a esta nueva rama de estudios clásicos.

Por último, en pleno siglo xx cabe destacar los importantes trabajos de S. Lieberman ${ }^{8}$, D. Sperber ${ }^{9}$ y H.B. Rosén ${ }^{10}$, que utilizan el importante aporte de los descubrimientos arqueológicos: inscripciones y papiros.

A su vez para los estudiosos de la lengua griega, especialmente de la кoเví en general y del Nuevo Testamento en particular, se despertó un especial interés por este vocabulario a través del cual se fue descifrando el "griego palestinense» utilizado en los primeros siglos. Por ejemplo el diccionario de Bauer ", en su original alemán y en su traducción inglesa, incluye la literatura rabínica («die rabbinische Literatur», «Rabbinical Literature») como una de sus fuentes detalladas.

Todos estos trabajos de lexicografia talmúdica y midrásica, que exigen una cuidadosa lectura de los caracteres hebreos y están destinados a interpretaciones y comentarios de la literatura rabínica, se basan en un esmerado estudio de la tradición clásica europea y a su vez reflejan los dramáticos cambios que hubo en estas disciplinas desde la Edad Media hasta nuestros días. Es decir, desde el riguroso método que se basa en el análisis filológico-lingüístico e interpretación textual de la literatura clásica hasta las nuevas escuelas surgidas después del descubrimiento de los papiros en el siglo pasado y del importante testimonio de las inscripciones.

Para los investigadores del "griego rabínico" todo aporte lexicográfico de las lenguas clásicas es vital. Dentro de los mismos debemos in-

' S. Krauss, Griechische und lateinische Lehnwörter im Talmud, Midrasch und Targum, Berlín 1898, dos vols. Una introducción y comentario a esta edición en H. B. Rosén, "Palestinian кoเvy in Rabbinic Illustration», JSS 8, 1963, pp. 56-72. Su gramática incluye un estudio sobre la fonología, el verbo, las áreas semánticas, etc. Krauss fue el primero que utilizó el término «Die rabbinische Gräcität», p. 221.

${ }_{8} \mathrm{~S}$. Lieberman, Greek in Jewish Palestine in the life and manners of the Jewish Palestine in the II-IV centuries C.E., Nueva York 1942; Hellenism in Jewish Palestine, Nueva York 1950; Selections from Greek and Jewish Palestine and Hellenism and Jewish Palestine, Nueva York 1962.

9 D. Sperber, A Dictionary of Greek and Latin Legal Terms in Rabbinic Literatu$r e$, Bar Ilan 1984.

${ }^{10}$ H. B. Rosén, «Palestinian koเvi...»; idem, L'hébreu et ses rapports avec le monde classique, París 1979; "Die Sprachsituation im römischen Palästina», en Die Sprachen im Römischen Reich der Kaiserzeit, Bonn 1980, pp. 215-239.

"I. Wauer, Griechisch-Deutsches Wörterbuch zu den Schriften des Newen Testaments und der übrigen urchristlichen Literatur, Berlín 1936 (traducción inglesa de W. Arndt y F. W. Gingrich, Chicago 1957). Sobre el griego rabínico cf. E. Schwyzer, Griechische Grammatik, Munich 1953, I, p. 154. 
cluir el nuevo Diccionario Griego-Español $(D G E)^{12}$, que se va transformando en un instrumento imprescindible para la preparación de todo trabajo científico. Dentro de sus importantes nuevas características debemos destacar: los amplios límites cronológicos (desde los orígenes de la lengua hasta el siglo vil d.C.), el exhaustivo estudio de papiros e inscripciones que fueron publicados en los últimos decenios y aún no fueron incluidos en ningún diccionario, el nuevo interés por la literatura patrística y, por último, el esmerado estudio de publicaciones científicas relacionadas con la investigación del griego y del estudio comparado con el indoeuropeo.

Nuestro estudio se basa exclusivamente en un solo texto rabínico: Génesis Rabba (Galilea, siglos III-v d.C.), y para cuya publicación se han utilizado los dos primeros fascículos del $D G E$ y su fichero. En el mismo nos limitaremos a traer ejemplos del "griego rabínico» en cuatro áreas: difusión geográfica (paralelos con Asia Menor, Siria y Egipto); interpretaciones textuales enriquecidas a base del fichero del $D G E$; vocabulario griego de Génesis Rabba no documentado previamente, y observaciones fonéticas y gramaticales.

\section{Difusión geografica (paralelos con Asia Menor, Siria y Egipto)}

La primera fuente "directa» para el conocimiento de la кoเví oriental la constituye el testimonio de los papiros de Egipto, y su aporte es indiscutible para el conocimiento y estudio del griego palestinense hasta fines del período bizantino. Dentro de esta categoria debemos también incluir los papiros que fueron descubiertos en el desierto de Judea ${ }^{13}$; aunque de muy reducido número, son también de gran valor para estos estudios. Mas debemos destacar que la historia política y administrativa de Erez Israel señala los lazos directos con Siria y Asia Menor ${ }^{14}$, así como las relaciones comerciales y culturales. Como prueba de ello, presentamos dos listas de palabras atestiguadas en Siria y Asia Menor y de forma paralela en Egipto para señalar la difusión e influencia en la formación del griego rabínico. En ambas listas hemos incluido también pa-

12 Véase bibliografia en el $D G E$.

13 Sobre los papiros griegos del Mar Muerto véase H. J. Polotsky, "The Greek Papyri from the Cave of the Letters", IEJ 12, 1969, pp. 227-258, y últimamente H. J. Wolff, «Römisches Provinzialrecht in der Provinz Arabia» en $A R N W 13,1980$, pp. 763-807.

14 Sobre una kouvi influenciada por el dialecto de uso en Asia Menor, véase Rosén, "Palestinian koเví...», p. 59. Cf. También A. Thứmb, Die griechische Sprache im Zeitalter des Hellenismus, Estrasburgo 1901, pp. 178-179. 
labras de origen latino, pero ya asimiladas al vocabulario del griego de la administración imperial. Estas palabras presentan los primeros rasgos del latín vulgar.

Para la preparación de este estudio contamos con dos importantes trabajos lexicográficos: H. J. Mason, Greek Terms for Roman Institutions, Toronto 1974, y S. Daris, Il lessico latino nel greco d'Egitto, Barcelona 1971, que ofrece una importante documentación papirológica.

\section{Asia Menor y Siria}

Génesis Rabba

$d w k s$

'eparkyh

frny

pltyh

pr'gmtwtyn

pylwn

qmrwtwn

qrmyd

Snhdryn
Fuentes y bibliografia

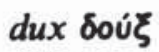

IGEphesos 737

MAMA III 73

Mason, p.39

énapXeía (provincia)

IGEphesos 3029

$\phi \varepsilon \rho v i$

IGEphesos 4.55,60

platea nhareta 'calle'

IGEphesos 3013,8

3071,22

3080,4

праүнатвитй 'comerciante'

'administrador'

MAMA 5,185

8,182

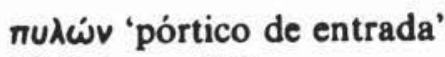

IGEphesos 437

канарштб́s 'arqueado'

ISmyrna 191,9

керані'

IGEphesos 20 a 48

ouvtoplov 'Sanedrín'

TAM 3 (1) 3 a (" d.C.) 


\section{EGIPTO}

dwnatybh

mylnyn

prgwd

ptrwn

'pwky

$q y l$

qyntryn

sygnwn

sttywnr donatiuum \&wvatiovov

POxy. 1047,4

Daris, p.43

$\mu \varepsilon \lambda a v$ 'tinta'

PMag. VII 26

paragauda napayaúdıov

'vestimenta decorada con púrpura'

Sammelb. 11075,11 (v d.C.)

Daris, p.88

patronus nátpowv

Daris, p. 190

dnoxý 'recibo, cuenta, pago'

PMich. 1604,21 (III d.C.)

PCair. Isidor, 13,27

cf. Rosén, "Palestinian koเví...», p.62

cella $\kappa \hat{E} \lambda \lambda a$

POxy. 1128,15

Daris, p.15

centenarium kevTqudpiov

'medida de peso (100 libras)'

POxy. 84,14

Sammelb. 9368.3,4 (vi d.C.)

signum olyvov

PLond. 2.412,12

Daris, p.104

stationarius otatiwvdplos

Daris, p. 109

cf. MAMA 8,340

\section{INTERPRETACIONES TEXTUALES ENRIQUECIDAS A BASE DEL FICHERO DEL $D G E$}

En esta sección serán presentados una serie de párrafos de Génesis Rabba en los cuales surgen palabras en griego. Estas últimas fueron interpretadas en los diccionarios tradicionales (Levy, Dalman, Jastrow, Kohut, etc.) en base a la tradición clásica. Presentamos aquí nuevas in- 
terpretaciones, evidentemente más acertadas y más relacionadas con el texto rabínico, basadas en el léxico de los papiros e inscripciones recopiladas en el fichero del $D G E$ y que reflejan la lengua común de uso diario de Egipto y Judea.

'n'lgyn (Génesis Rabba 28,1)

El Santo, Bendito sea su Nombre, no castiga (literalmente no cobra sus cuentas) a los malvados hasta que no lee sus ' $n$ 'lgyn.

Este término ('n'lgyn) se ha interpretado en los diccionarios talmúdicos (Levy, Jastrow, Dalman) como identificado con dvaגoyeĩov 'atril, mesa de lectura'. En la nueva interpretación sugerida correspondería a dvaגoyń 'cuenta', 'factura', registrada en el Sammelb. 4425,3 (II d.C.). Probablemente su nom. sing. sería ' $n$ 'lgy. Esta interpretación aclara el párrafo completamente: «El castigo no llega hasta que Dios no lee la cuenta (de pecados) de los malvados».

dlțwryh (Génesis Rabba 19,9)

Comenzó (la serpiente) a hablar dltwryh sobre el Creador.

La palabra dltwryh fue aceptada por los lexicógrafos de rabínica como proveniente del latín delatoria, un neutro plural acusativo en función de sustantivo, que no está atestiguado en griego. Mas el catálogo

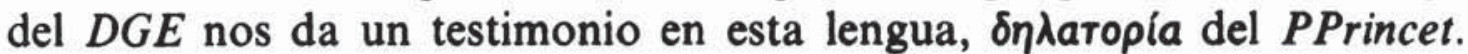
119 , líneas 24, 38 y 53, con el significado de 'calumnia, difamación' (por evasión de pago de impuestos). El papiro corresponde al período de Diocleciano (siglo Iv) y es contemporáneo del texto rabínico.

dyprwspwn (Génesis Rabba 8,1)

Cuando el Santo, Bendito sea su Nombre, creó al hombre dyprwspwn (de doble rostro) lo creó.

La interpretación comúnmente aceptada por comentaristas y filólo$\operatorname{gos}^{15}$ es la de una clara alusión al relato de Platón, Symp. 189 e прббwna $\delta$ úo. Pero el testimonio de los papiros de Egipto enseña que la expre-

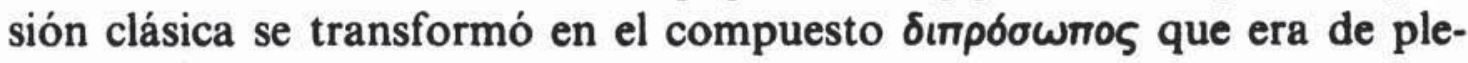

is Sobre el texto rabínico y el uso de la fuente del Banquete de Platón véase $\mathrm{J}$. Freudenthal, Hellenistische Studien, Breslau 1874. 
no uso común en la kouví para señalar doble faz (de las telas, PMich. 680, 10, o de los lados de las paredes, PZen. 59764) ${ }^{16}$.

lyps (Génesis Rabba 42,3)

(¿A qué se parece este ejemplo?), a un estado que debía su lyps al ministro del reino.

Acrobáticamente el término lyps fue interpretado como גoınás 'restante' (¿restante de qué?).

Un importante nuevo aporte de los papiros de Egipto aclara todo el

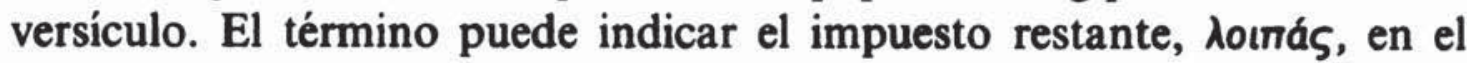
Imperio Bizantino. Así figura en el POxy. 3415,9-10, que corresponde al siglo iv d.C.

fyly pwtyryn (Génesis Rabba 10,7)

Cuando llegó a Roma (el conquistador Tito, después de haber destruido el Templo de Jerusalén) entró en unas termas. Al salir de allí le entregaron un fyly pwtyryn para beber, pero en ese momento penetró un mosquito en su nariz... (aqui comienza el relato del castigo divino por la destrucción del Templo).

La identificación de los términos rabínicos en cada una de las dos vasijas $\phi ı ́ d \lambda \eta$ у пот́́pıov, de uso común en el oriente helénico, es clara e indiscutible. Mas el importante nuevo aporte de los papiros es el uso de las dos juntas para indicar una ofrenda sagrada en el Templo (Sammelb. $11.478,10)$ y también véase el diccionario de F. Preisigke, s.u. notrípiov.

El uso de los términos juntos alude a la divinización de Tito y al inmediato castigo.

tymlyws (Génesis Rabba 83,1)

Este ejemplo (es como el de un rey que quiso construir un palacio). ¿Qué hizo? (El rey, alusivo a Dios) prendió velas y antorchas para saber dónde colocar los tymlyws del Universo.

El término tymlyws fue correctamente identificado por los lexicógrafos con el término $\vartheta \varepsilon \mu \varepsilon \lambda \iota_{1} \varsigma$ 'fundamento'. Mas un estudio más detallado del importante testimonio epigráfico de este período enseña que este término tiene también una connotación religiosa. Así, por ejemplo, una

16 Otras fuentes: PZen. 764,3 y PMich. 38,10. En hebreo moderno dw-przwfy 'ambiguo' como Luc., I.Tr. 43. 
inscripción de Asia Menor, publicada por D. Knibbe ${ }^{17}$, incluye una oración a los dioses que aseguran los "fundamentos" del terremoto.

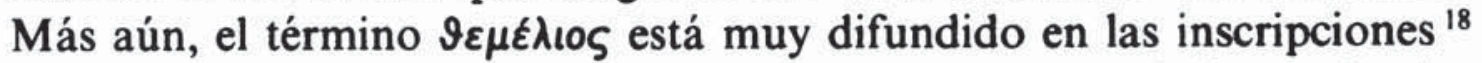
de las sinagogas de Palestina y de la Diáspora para señalar su fundación y solicitar la bendición para su construcción.

\section{Vocabulario griego de Génesis Rabba no documentado PREVIAMENTE}

El texto de Génesis Rabba, cuyo vocabulario griego está atestiguado en fuentes de la koเví y del bizantino incluye también palabras no documentadas en textos griegos, inscripciones y papiros, ni registradas en ningún diccionario clásico. Presentamos aquí algunos ejemplos y sugerimos una interpretación.

'ntyqysr (Génesis Rabba 53,10)

... el rey de Jericó y su 'ntyqysr ("dvrıkaíap).

El rey y su Pro-Caesar. En el presente caso el prefijo ávtL- señala el 'virrey'.

dygmtryn (Génesis Rabba 11,10)

... sino que Dios actúa con éstos (los justos) y con aquéllos (los malvados); hace que éstos se vean en su dygmtryn y aquéllos en el suyo.

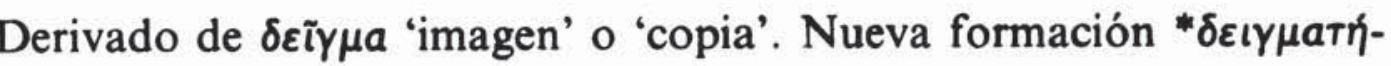
piov.

dyfwryn (Génesis Rabba 18,5)

... (la generación del Diluvio). Su esposa es la que da el divorcio y ella le paga dyfwryn.

De $\delta u+\phi \varepsilon \rho v \eta$ 'dote'. Una nueva formación para indicar doble dote,

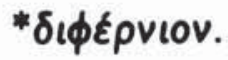

glasynwn (los vestidos de Adán y Eva, Génesis Rabba 20,12)

${ }^{17}$ L. Robert, $B E G$ (en $R E G$ ) 81,1968, n. ${ }^{\circ} 465$.

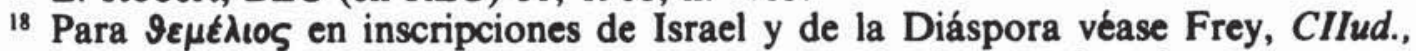

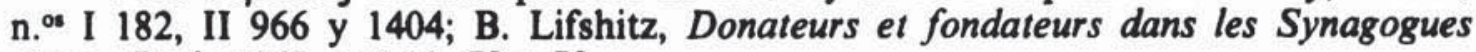
Juives, París 1967, n. ${ }^{\circ 11}, 72$ y 79. 


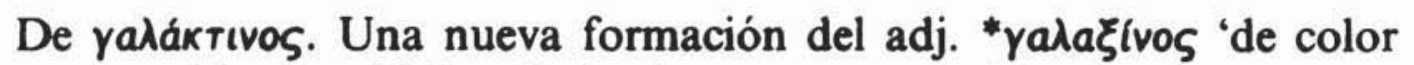
blanco o emblanquecido' y cf. Stephanus, s.u. yaגaßaĩos.

gmwmsyh/gmsyh (Génesis Rabba 26,5)

No fueron borrados (los pecadores) del Universo (por el Diluvio) hasta que no escribieron gmsywt [plural hebreo] para hombre y bestia.

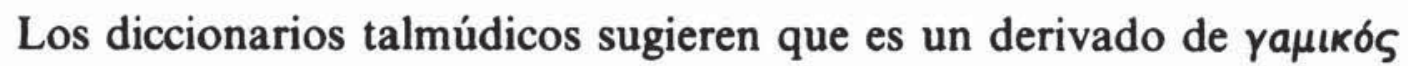
contrato matrimonial POxy. 1034,5.

Mas el contexto de todo el párrafo exige una explicación más deta-

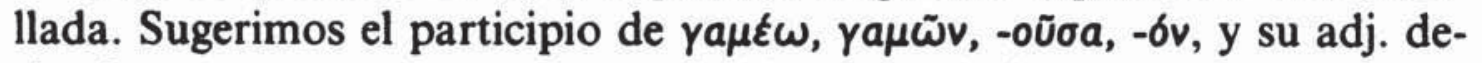
rivado yapovoíos, $-a,-o v$, que probablemente alude a relaciones sexuales ilícitas pero «legalizadas». Cf. su uso en el griego moderno.

Klp'ndr (Génesis Rabba 50,3)

Nombre de uno de los jueces de Sodoma. Apelativo formado por $K \lambda \varepsilon \pi(\tau)+a v \delta \rho \circ \varsigma$ cuyo sentido es 'ladrón de hombre'. Compare también

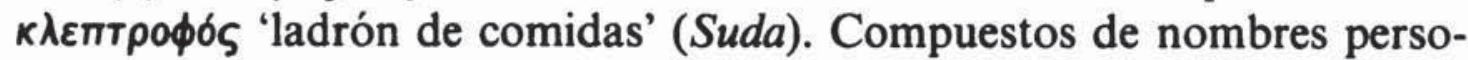
nales formados con un segundo elemento -avסpos son comunes desde el

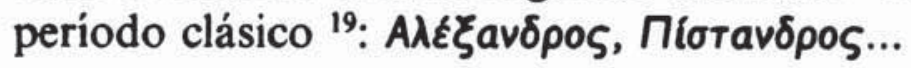

Mttrwn (Génesis Rabba 5,4)

Se hizo la voz del Santo, Bendito sea su Nombre, Mțtrwn sobre el agua.

El nombre de este ángel surge en la literatura apocalíptica (Henoc), y posteriormente en la literatura mística, midrásica y talmúdica. Es representado como enviado directo de la voluntad divina. Sobre el origen del nombre ${ }^{20}$ se han dado diversas teorías, pero la más aceptada hasta

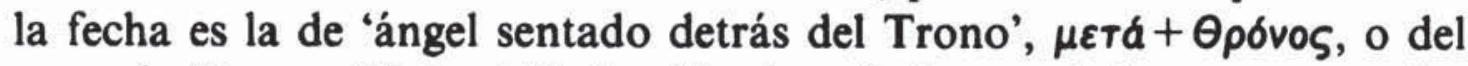

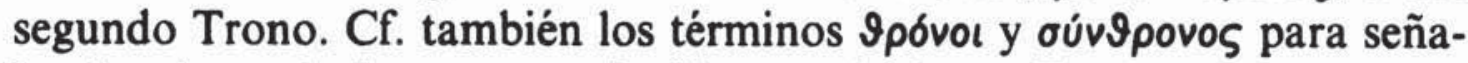
lar ángeles en la literatura apócrifa y en el Nuevo Testamento.

${ }^{19}$ F. Dornseiff-B. Hansen, Reverse Lexicon of Greek Proper Names, Chicago 1978 , p. 280.

${ }_{20}$ Sobre Metaţron véase S. Lieberman, «Metatron. The Meaning of his Name and his Functions", en I. Gruenwald, Apocalyptic and Merkavah Mysticism, Leiden 1980, pp. 235-244; G. Scholem, "Metatron», Encyclopaedia Judaica, XI, cols. 14431446, y el art. de A. Navarro en Apócrifos del Antiguo Testamento, ed. A. Díez Macho et alii, IV, Ciclo de Henoc, Madrid 1984, pp. 215-216. 


\section{OBSERVACIONES FONETICAS Y GRAMATICALES ${ }^{21}$}

La transcripción del griego en caracteres hebreos es importantísima para reconocer variantes fonéticas que son resultados de relaciones históricas: (del clásico a la koเví y de la koเví al bizantino), o sincrónicas: variaciones de dialectos. Esta sección de nuestro estudio está dedicado a presentar ejemplos de transcripciones que atestiguan importantes fenómenos fonéticos del clásico, de la kotví y del bizantino y de períodos de transición entre ellos.

Al presentar este material debemos reconocer tres limitaciones: a) Procesos fonéticos propios de las lenguas asimiladoras (hebreo/arameo). b) Si bien el texto de Génesis Rabba fue redactado en el periodo bizantino (siglos IV-v d.C.) el origen del griego palestinense data del siglo IV a.C. con reconocidas influencias de distintos dialectos de origen helénico. c) La tradición de los mss. de Génesis Rabba ${ }^{22}$, considerada una de las mejores de la literatura rabínica y sobre la cual se basa nuestra lectura, no es directa y la mano de copia imprimió su sello sobre la ortografia del texto. Por estas tres razones nos limitaremos únicamente a aquellos fenómenos fonéticos que están atestiguados en las inscripciones de Israel y/o citados en la investigación del griego. Por último, completaremos este estudio con nuevas formaciones gramaticales que anuncian el griego moderno.

a. El itacismo ${ }^{23}$

El itacismo es uno de los fenómenos fonéticos más característicos de la koเví desde sus orígenes hasta épocas modernas.

$\eta=[\mathrm{i}]$

Griego

doوعvís

dexidporins

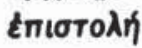

$\pi \eta \gamma \dot{n}$
Génesis Rabba

'stnys

'rǩylysțys

'pysțwly

pygy

${ }^{21}$ Detallada descripción de los fenómenos fonéticos característicos de la koเvi en Rosén, «Palestinian koเví...», pp. 65-66. Cf. también F. Blass-A. Debrunner, $A$ Greek Grammar of the New Testament and other Early Christian Literature, trad. R. Funk, Chicago 1961, especialmente pp. 11-19.

${ }_{22}$ Sobre los principales manuscritos de Génesis Rabba y su aporte al estudio del arameo palestinense véase E. Y. Kutscher, Studies in Galilean Aramaic, Bar Ilan 1976, pp. 11-41.

${ }^{23}$ En la tradición de los manuscritos la $Y$ (yod) puede también representar el șere [e]. Véase la nota de A. Sáenz Badillos, «El hebreo del s. II d.C. a la luz de las transcripciones griegas de Áquila, Símmaco y Teodoción", Sefarad 35, 1975, p. 8. 


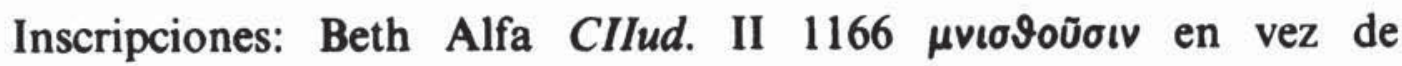
$\mu v \eta \sigma \vartheta \tilde{\omega} \sigma \iota$.

$u=[i]$

La $v{ }^{24}$ fue la última de las vocales que sufrió el fenómeno del itacismo, posterior a la contracción del diptongo o $>$ ı.

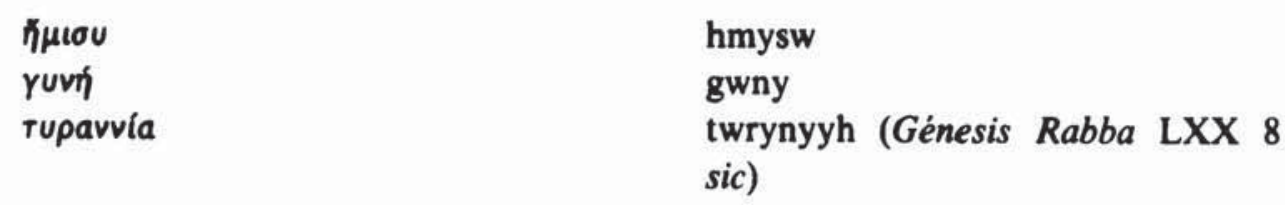

b. Contracción de los diptongos

La contracción del diptongo ou $=[\mathrm{u}]$ es conocida desde el período clásico.

$\begin{array}{ll}\text { Boudri } & \text { bwly } \\ \text { Boupydosios } & \text { bwrgr } \\ \text { oúoia } & \text { 'wsy' } \\ \text { oúykia } & \text { wnqy }\end{array}$

$\varepsilon \iota=[\mathrm{i}]$

$\varepsilon$ elkóviov

'yqwnyn'

Inscripciones: Gerasa, inscripción publicada por J. Pouilloux en $L A$

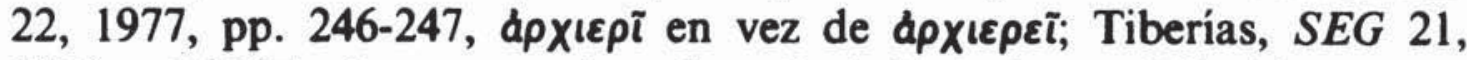

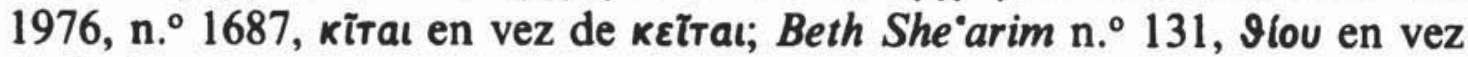
de 9eíou.

$\mathbf{o} \mathbf{l}=[\mathrm{i}]$

Una contracción más tardía que los demás procesos fonéticos.

\begin{tabular}{|c|}
\hline olkoupévn \\
\hline
\end{tabular}

24 La $v$ sufrió un itacismo posterior a otras vocales y mantuvo su valor aproximadamente de ot cuando ya la $\eta$ se transformó en t. Véase Rosén, "Palestinian кoเvif..., p. 65. En una inscripción de Beth Alfa, CIIud. II 1166, aparece is тยXvite i

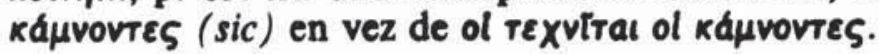


El conocido proceso de las contracciones de $105>15$ y $\operatorname{lov}>$ iv es también atestiguado en el griego rabínico. La terminación iv se asimila con el plural en arameo $Y N$ (hebreo $Y M$ ).

$$
\begin{aligned}
& \text { Buldápiov } \\
& \text { Siokáplov } \\
& \text { KEAגápiov } \\
& \text { кooúápiov } \\
& \text { патв } \lambda \text { Aikiov }
\end{aligned}
$$

\begin{tabular}{|c|c|}
\hline 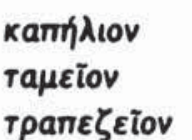 & $\begin{array}{l}\text { qplywn } \\
\text { tmywn } \\
\text { trpyzyn }\end{array}$ \\
\hline
\end{tabular}

$$
\begin{aligned}
& \text { bwlryn } \\
& \text { dysqryn } \\
& \text { qylryn } \\
& \text { qwzmryn } \\
& \text { pțylqyn }
\end{aligned}
$$

Este mismo proceso produce las contracciones de $\varepsilon \operatorname{lo\varsigma }>15$ y $\varepsilon \iota 0 v>\imath$.

Inscripciones: Bašan, SEG 23, 1978, n. ${ }^{\circ} 1341, \mu v \eta \mu i ̃ o v$ en vez de $\mu \vee \eta \mu \varepsilon \tilde{o v}$.

\section{c. Consonantes}

1. Asimilación parcial

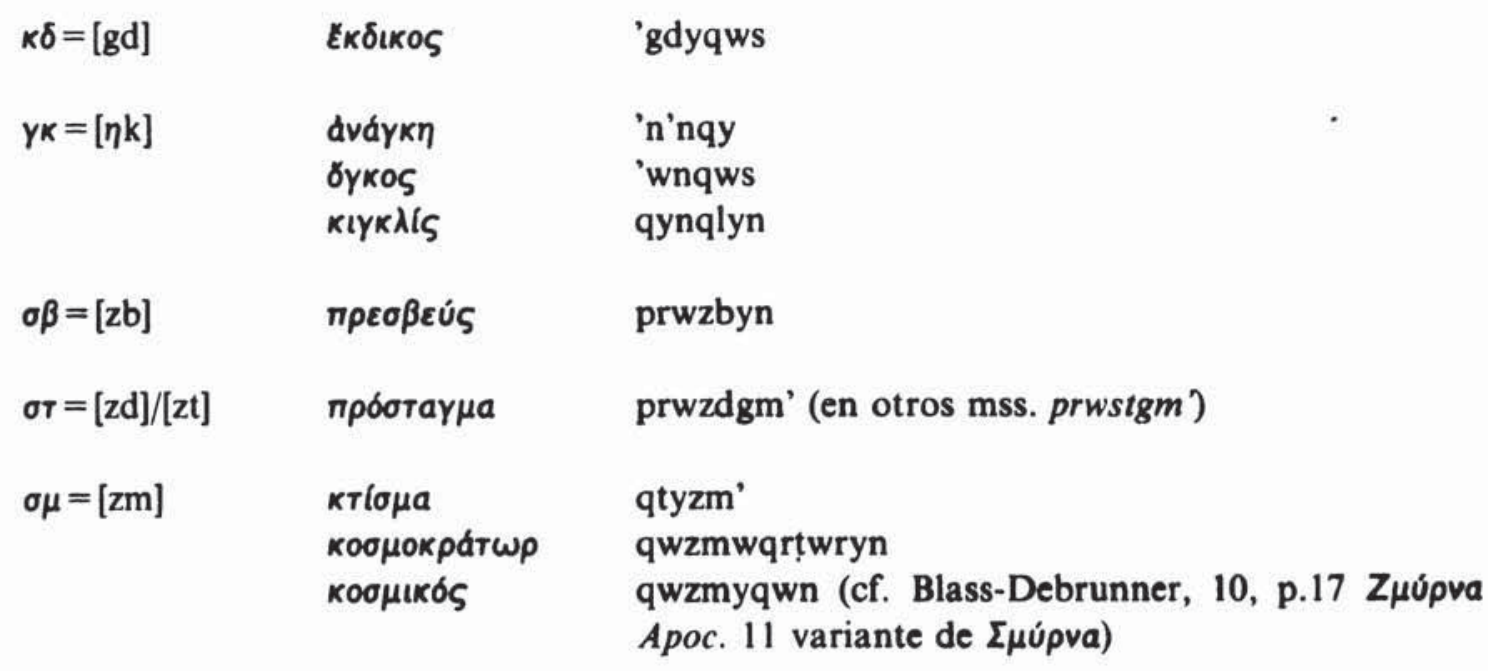

2. Transición de una articulación explosiva de [b] a una labiodental fricativa $[\mathrm{v}]$

Por último, uno de los más clásicos fenómenos fonéticos de la koเví tardía y del bizantino es la transición de una articulación explosiva de [b] a una labiodental fricativa [v]. Para reflejar gráficamente la primitiva articulación se acude a un infijo nasal labial [mb]. 
La $u$ latina va a ser representada en el griego por ou y posteriormente por $\beta$. En hebreo/arameo por beth (B) y por vav (W/V).

\begin{tabular}{|c|c|}
\hline $\mathrm{V}=$ beth & $\begin{array}{l}\text { oúpıód́plos } \\
\text { (ueridarius) }\end{array}$ \\
\hline $\mathrm{V}=v a v$ & $\begin{array}{l}\text { Byhov } \\
\text { (uelum) }\end{array}$ \\
\hline
\end{tabular}

Inscripciones de Israel:

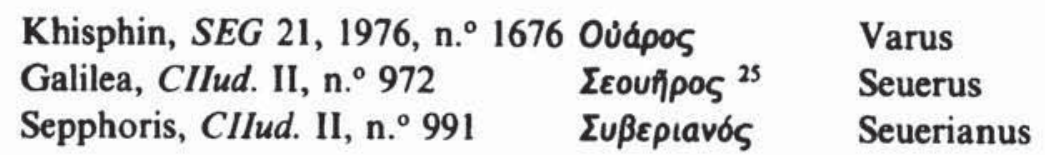

\section{d. Formaciones nuevas}

La transcripción de caracteres hebraicos permite también detectar formaciones nuevas del griego que van anunciando la lengua moderna. La importancia de estos testimonios no sólo radica en la formación morfológica, en muchos casos ya reconocida por los investigadores, sino en la cronología que precede a veces en varios siglos a la comúnmente aceptada en la investigación.

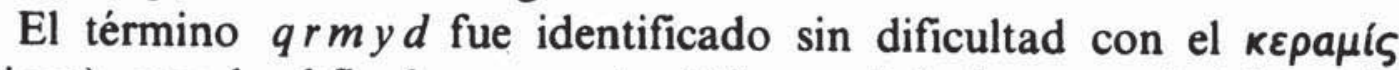
(griego), mas la $d$ final aparece también en el árabe y en el siriaco, lo que nos indica que es radical.

Sugerimos que es un nuevo nominativo que fue formado a partir del

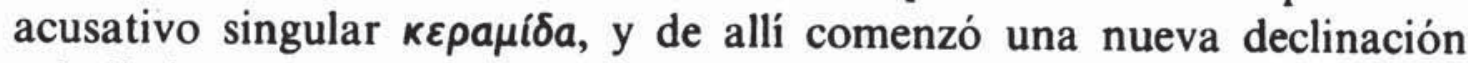
asimilada por el arameo y por otras lenguas del medio semítico.

En una formación similar qynrs, que fue identificada con kıvápa 'alcachofa', esta forma surgió de un acusativo plural kıvápas del cual se derivó una nueva declinación.

En los textos rabínicos aparecen las formas ' $r \underline{k} w n$ y ' $r \underline{k} w n t \underline{t} s$, que fueron identificadas sin dificultad con a $\rho \times \omega v$. Mas la segunda formación nos indica que ésta fue formada a partir de un acusativo plural ăpxwrtas, del cual se derivó una nueva declinación que justifica el ' $r \underline{k} w n t \underline{s}$ en hebreo y arameo.

Por último, en el texto de Génesis Rabba surge un superlativo $p r$ 't't' 'primero' прம́тата, que es una normalización popular del superlativo clásico $\pi \rho \tilde{\omega} \operatorname{ro\varsigma }^{26}$. Cf. la formación en griego moderno

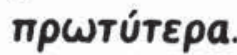

${ }^{25}$ La letra $\eta$ no sufrió el itacismo delante de $\rho$, véase Rosén, «Palestinian koเvi...", p. 64.

${ }^{26}$ Sobre $\left.\pi \rho \tilde{\omega} т\right)_{\text {y }}$ y sus otras formaciones véase Schwyzer, I, pp. 539, 595. 


\section{RESUMEN}

En el presente estudio hemos presentado ejemplos de la importante contribución del conocimiento del griego rabínico para el estudio de la кoเv́n y su aporte para apreciar los desarrollos fonéticos y gramaticales de esta lengua. Esta rama de los estudios clásicos está intimamente ligada a toda la investigación de las fuentes literarias, inscripciones y papiros del oriente helénico, y existe una mutua relación entre ellos.

Por su especial carácter interdisciplinario de estudios clásicos, semíticos y arqueológicos, el griego rabínico exige un riguroso y contrastado aporte de las distintas áreas de estudio. Sólo un metódico y continuo estudio de estas fuentes y la colaboración entre los distintos centros de investigación permitirá lograr los resultados deseados en el futuro.

Shifra SzNol 